$\S=-1$

\title{
A Comprehensive Review on Energy Management Strategies in Hybrid Renewable Energy System
}

\author{
Ch.Laxmi $^{1}$, Dr.M.Narendra Kumar ${ }^{2}$, Dr.Sushant Kumar Mandal ${ }^{3}$ \\ ${ }^{1}$ Research Scholar, Centurion University Of Technology And Management, Odisha,India \\ ${ }^{2}$ Professor,St.Peters Engineering College,Telangana,India \\ ${ }^{3}$ Professor, Centurion University Of Technology And Management,Odisha,India \\ *Corresponding Author E-Mail:Laxmichanumalla@Gmail.Com
}

\begin{abstract}
The diffusion of renewable sources of energy has been increased because they reduce the environmental influence and meet the increase in demand of energy. The key feature of the renewable source of energy is their changeability and irregularity. These draw backs are overcome by combining the non-conventional sources through storage and back up. However the incorporation of renewable sources of energy makes the system more complex in respect of energy sharing, control and analysis. The main objectives of energy management configuration are to ensure the maximum exploitation of renewable sources, continues power supply to the load, lessen the rate of energy production and increase the steadiness of the system. To accomplish these purposes efficient and fast control techniques are required which are proficient of handling information perceptively and captivating acute decisions vigorously inside the operative limitations. This paper presents an explicit review of energy management approaches currently existing and those now in research for the smooth process of hybrid system with renewable sources.
\end{abstract}

Keywords: Fuzzy, HOMER, linear programming, neural network.

\section{Introduction}

The ideal energy consumption to the extreme degree is possible by effective energy monitoring. And it includes operation and scheduling of energy making and consumption. The minimum social benefits and maximum social benefits are achieved by energy monitoring system. The chief goal of energy controlling is to produce a appropriate set of operation points for renewable sources of energy in such a manner that cost effectively optimized power dispatch is maintained to satisfy a certain level of demand .The objective and application of an energy control system are energy usage analysis, energy cost allocation, electrical distribution benefit management and demand response. The conservative methodologies for controlling hybrid power systems, like PI controller are slow, instable and not applicable for the system by change in weather conditions. This directed to the advancement of more intelligent techniques which are potential of handling all the dynamic changes. This paper analyses the energy management schemes used in renewable power systems, special attention towards the isolated hybrid renewable sources of energy and systems connected with the grid is attempted.

Number of energy monitoring approaches are proposed and described in the works proposed such as AI techniques, Fuzzy logic, optimal control approaches and model based predictive controllers. S.M.Zaharee, M.Khalaji Assadi and R.Saidur [1], appraised different optimization methods using artificial intelligence in hybrid energy arrangements, like genetic algorithms, simulated annealing also particle swarm optimization Erdinc O and Uzunoglu M [2], interpreted various approaches for Optimum Scheme of hybrid system with renewable sources of energy. Wang and Nehrir [3], projected a "strategy for the energy observation in hybrid system containing wind, photovoltaic and FC which linked by ac load. Ahmed et al. [4], deliberated power fluctuation in photovoltaic, wind and FC through power strategic management. R. Carapellucci, L. Giordano [5], established generation of energy in island mode considering non-conventional systems along with backup. Sanjit Kumar Kaper and Niraj Kumar Choudhary [6], presented an "extensive assessment of power management, stability concerns for micro grid and addressed the prominent issues of power management". Upadhyay S, Sharma MP [7], appraised the methodologies used for sizing and monitoring in an energy system with renewable arrangement.

\section{Hybrid Energy System}

Hybrid renewable systems help to mend power quality and increase system reliability. The need of integrating different renewable sources of energy deploying appropriate power management stratagem is required because of certain challenges comprises erratically fluctuating renewable sources of energy like wind speed, solar radiation partial period of energy storing devices and high initial installation cost, which causes the fluctuations in source and load power The hybrid system shown in the fig. 1 consists PV, wind generator, fuel cell, electrolyzer and battery. The photovoltaic system supplies the load, when load demand decreases the superfluous energy is consumed by the electrolyzer. The process of is carried out in electrolyzer where the water gets splits into $\mathrm{O}_{2}$ and Hydrogen. The fuel cell input is obtained through the stored hydrogen. The battery uses the additional energy. 


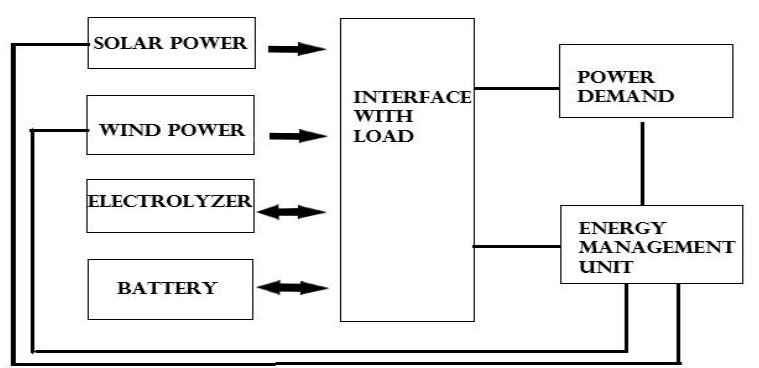

Fig. 1: Block diagram of Hybrid energy system

Despite the benefits of hybrid system, some drawbacks which are serious mean to be overcome for the satisfactory operation. These include stability issue when abrupt variation of load or unexpected transformation of output power from a source occurs, reliability of power from weather dependent power sources are used, suitable load distribution between the sources to ensure the efficient operation and when batteries utilized for storage purpose they further increases the maintenance cost. Hybrid systems with integrated sources are designed in different possible configurations. Dc bus with central control arrangement and AC bus with central control approach are the two types of series hybrid system. In dc-bus with central control, the dc bus is connected with the non-traditional sources of energy, batteries and loads. In ac-bus with central control, the ac bus is connected by sources, batteries and loads. The major constraint of system is to synchronize the source frequency and voltage magnitude with the inverter parameters.

\section{Energy Management Strategies}

\subsection{Conventional Control Strategies:}

The hybrid energy by renewable system necessitates special energy monitoring approaches for minimizing operating cost and efficiency improvement. There are few stereotype techniques depending on linear programming and PI controllers which are prominent for effectively operate the hybrid renewable systems. M.Vaccari et al. [8] developed an optimization scheme with regard to Linear Programming with sequential (SLP) algorithm for common hybrid energy by renewable system. The proposed method lessens the running costs by generating an operating plan over a specified time horizon of the set points of each device.

A hybrid power with regenerative capability containing a photovoltaic and wind power, employing grid-tie system and UPS is proposed in [9] for significant loads. A power balance manage plan is proposed, which utilizes the power which is regenerated in a more effective way and ensures the continuous power supply for the load. Morias $\mathrm{H}$ et al. [10] presented the best possible process of wind energy, solar system, FC and battery using linear programming employing mixed integer method .E. Dursun and O. Kilic [11] evaluated the isolated hybrid system under special strategies of power control; the system employed by photovoltaic, wind and fuel cell. The primary supply source is given by photovoltaic and wind sources. The backup source is offered by fuel cell The continuous energy flow is achieved through the utilization of the FC. The required power of the load is divided between primary sources and the power management strategy maintains the battery SOC. The electrolyzer is run by the surplus power generated, this happens when the power generated is extra than the demand and the battery SOC is within limits. However, when the power required is high, the FC supplies the load and also charges the battery. Gupta A et al [12] developed a model under steady state in a hybrid system referring to a bio gas, photo voltaic system, a biomass, mini hydro and a diesel generator. The linear programming method is used for the calculation of ideal sizing for the system and implements the optimal dispatch policy. P.L. Zervas et al. [13] presented an optimal control model for system with hybrid generation of power containing solar cells and FC. P. Thounthong et a
[14] explained "The energy supervision of FC, PV array and super capacitor producing hybrid generation of power. Ipsakis et al. [15] elucidated how the change in the size of the hysteresis band affects the operation of the power generated by hybrid sources controlling scheme and evaluated two power management methods performance that utilize the hysteresis band in hybrid arrangement, which contains wind generation, photo voltaic and hydrogen. hang et al. [16] introduced " an energy monitoring strategy acting on power flow control for off-grid systems", with the mean of keeping the charge state (SOC) of the batteries inside a definite range and evading over-discharge, over-charge and limiting the changeover between charge and discharge through power constraints of loads and primary sources.

Diego Feroldi et al [17] developed favorable sizing method by the application of genetic algorithm which showed the improvement in sizing of a system with hybrid nature. In this power generated through wind turbine, solar and bio ethanol are considered. The supply to the FC is given by hydrogen which is generated by the bio ethanol. BenoîtRobyns et al [18] described various methodologies for regulation of hybrid energy sources based on backup system.

Liao and Ruan [19] proposed a Power managing scheme for a separate PV array and battery power system. The energy under steady state is supplied by the PV system and the dynamic energy is by the battery. Based upon the weather conditions and SOC of the battery the dc-dc power electronic device is controlled in bidirectional mode. The energy monitoring strategy ensures high efficiency and smooth operation of the system under steady state and dynamic conditions. Dahmane et al. [20] presented "An algorithm for the energy monitoring of a isolated hybrid system comprising PV array, wind source, diesel generator, and battery storage". The PV array is operated in first priority mode and supplies the energy to the load. If it fails to operate due to weather conditions then the wind source operates at second priority. If both PV and wind unable to supply then the diesel energy will supplies the load. Bhakta et al. [21] used HOMER for the optimum performance and proper sizing and executed the financially viable investigation of a PV/wind hybrid system including a storage bank. Sen and Bhattacharyya [22], proposed an optimization control for a isolated system with hybrid method by using HOMER.

\subsection{Advanced Control Strategies:}

The conventional techniques like linear PI controllers are adopted for solving number of issues. Still in some special conditions like energy by renewable forecasting, storage forecasting and demand forecasting the results are unsatisfactory. Hence the traditional techniques are to be replaced with intelligent techniques.

In current period, number of studies has been proposed on contemporary techniques like genetic algorithm (GA), differential evolution (DE), neural network, fuzzy system, and neuro-fuzzy. Abedi et al. [23] developed an optimum power managing strategy of integrated renewable system comprising of various energy sources and storage systems. The proposed technique is assessed on a system with most largely used sources including wind source, PV source, FC, electrolyzers, tanks with hydrogen, diesel generators and batteries,. The chief aim of the paper accounts for optimization the power management which reduces the running cost and satisfies the load demand. The demand of the load is supplied by the sources PV source and wind source, the surplus energy is used for charging of the storage system. A differential evolution algorithm utilizing fuzzy system was developed for the optimization nonlinear multi objective system. Barley and Winn [24] presented predictive energy monitoring strategy by assessing the prospect load and supply states in an isolated wind power/diesel power/battery hybrid power system. A comparative analysis is made between non predicted management strategies and modeled energy monitoring strategy which showed that the developed method is cost effective method in the hybrid system. An online energy managing approach for the operation in real time of micro grid is developed by Wenbo Shi et.al [25]. The online energy monitoring 
is derived from the lyapunov optimization and implemented in a real micro grid system.

Mehdi Dali et al. [26] proposed an optimal control energy managing methodology in a hybrid system including PV array, wind power and batteries. An estimated and investigational validation is performed for the hybrid system. The system behavior in dynamic conditions is analyzed by the projected model and the control strategies showed the effective energy monitoring strategy. Zoubir Roumila et al. [27] developed an advanced control with supervisory attribute depending on fuzzy system for a hybrid power generation which includes Wind sources, Photovoltaic system, and Diesel generateon with battery storage. On account of weather conditions the operating processes of the hybrid system is studied.

Kwi-SeongJeong, Won-Yong Lee and Chang-Soo Kim [28] enlighten different power managing strategies utilizing fuzzy logic for a fuel cell system and storage by battery hybrid system. Mehdi Hosseinzade and Farzad Rajaei Salmasi [29], presented the effectively management of power in standalone micro grid with AC/DC buses by the adoption of fuzzy system and bank of batteries. Baziar A, Kavousi Fard A [30] developed an advanced algorithm which depends on PSO. The uncertainties such as errors in forecasting of the load, changes in grid, PV array and wind power intermittent generation are considered and the adaptive optimized algorithm made operation satisfactorily for the hybrid system. Feroldi et al. [31] proposed a management scheme for hybrid isolated system which is composed of wind source, solar cell, and bioethanol power sources. The FC is supplied by hydrogen which is from the bioethanol reformer. During the intermittency in the power generation from PV and wind the load demand is met by the fuel cell. An energy monitoring strategy is developed accounting by the significances and constraints making an optimal power balance between load power and power available. A.Tabanjat et al [32] developed an artificial intelligent approach for the operation of a hybrid system generating power. The AI controllers ensure the efficient and optimized operation in a system with hybrid generation of power. The Hybrid power system comprises wind sources and PV system as chief energy by renewable sources and the backup is attained by the FC and gas micro-turbine .The storage system integrated to conquer the undesirable effects due to weather conditions.

Bruni et al. [33] developed a predictive controller method for the examination of power managing which depends on the weather forecasts. The system comprises PV system, Fuel cell and battery. The control strategy ensures the minimization of the operating cost and improves the operating conditions .Basir Khan et al. [34] proposed distributed energy monitoring system for system generating hybrid power from the sources. The proposed system offers the control of each energy source and load using multi agent system. Brka et al. [35] designed a laboratory-scale system and presented a predictive controlled energy management strategy. Upadhyay and Sharma [36] described "Three different energy monitoring strategies defined as cycle charging, peak shaving, and load following". Diversified optimization techniques are applied for sizing of the hybrid system. The efficient computational capability, intelligent technique and adaptive property made neural networks as the most frequently used technique .The neural network is emerging as the effective control technique adopted in hybrid system supervision and control [37]. Behnke et. al. [38] presented an energy monitoring strategy based on neural networks for a hybrid system including PV, wind, diesel, and a battery. An effective control strategy was developed for the constraints for each source unit, mode of operation and load demand at consumer side. The proposed system minimized the price for operation and also meets the load demand. Azmy and Erlich [39] presented an energy managing strategy depending on artificial neural network approach for effective performance of integrated system. The proposed approach showed the fast and effective control of the power which reduced the operating cost. Hatti and Tioursi [40] developed an advanced model using neural network and proved that the model provided effective control and stable operation. YuKai Chen et al [41] designed an energy monitoring strategy in a
DC micro grid depending on fuzzy system which improves the battery life. O Erdinc. et. al [42] proposed an energy monitoring strategy based on fuzzy system and wavelet application, where the fuzzy system controls the power and wavelet was used for the examination of signals

\section{Energy Flow Management Control}

In integrated energy by renewable sources, to ensure continuous power supply to the load energy flow management is essential. The incorporation of non-conventional sources of energy leads to stability problems and power quality issues which are very serious. Therefore, it is necessary to manage the system optimally to conquer the difficulties caused by them. Normally the control techniques used in integrated energy by renewable sources for power flow management is classified into three categories; centralized control arrangement, distributed control arrangement, and hybrid centralized and distributed control arrangement.

\subsection{Centralized Control Arrangement:}

In the control arrangement central approach, for each renewable power source there will be a slave controller and all the slave controllers are associated with a master controller, it coordinates with all renewable power resources and slave controllers as depicted in fig.2. The master controller monitors the flow of energy among the load and the energy sources depending upon the given reference values and boundaries. The master controller acts as an energy controller. Depending on the signals obtained, set objectives and limitations it generates the control signals. In view of the available main and back up sources and in coordination with the demand of the load which optimizes the flow of energy.

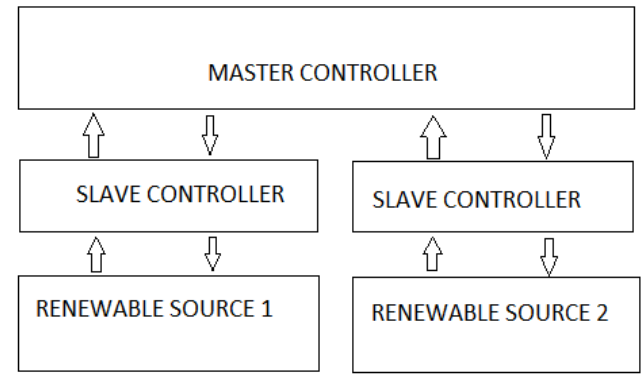

Fig.2: Centralized control arrangement

Valenciaga et al. [43] developed "Master control for PV- windbattery integrated system". The controllers keep up the load demand and also maintain the charge state of the battery which improves the battery life. Zaheeruddin and MunishManas [44] presented an efficient energy monitoring strategy using a central controller in an integrated renewable source comprising of wind source, solar cell, biogas and battery. In view of the demand of the load and generation from the sources the decisions were taken by the central controller to establish the efficient energy monitoring system.

The centralized control structure is most useful in integrated systems when the objectives are multiple and needs a common most favorable solution, but it suffers from some drawbacks like longer computation time and reliability.

\subsection{Distributed Control Arrangement:}

In the control arrangement with distributed approach, the control signals are sent to local controllers as depicted in Fig. 3. The local controllers communicate with each other to take appropriate decision for a given control law. The control arrangement with distributed approach improves the reliability as it overcomes the problem of single point failure [45]. 


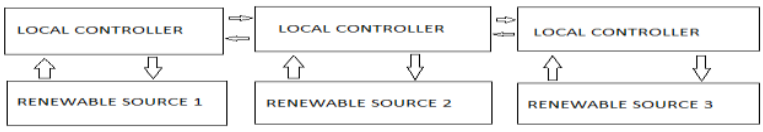

Fig.3: Distributed control arrangement

However, the distribution control structure suffers from complexity in communication amongst local controllers. These issues are solved by applying artificial algorithms like fuzzy techniques, artificial intelligence techniques, genetic algorithm and their mixed combination. A system with multi agent is widely used and it is the most appropriate approach for the integrated energy by renewable source.

\subsection{Hybrid Centralized and Distributed Control Ar- rangement}

Centralized and distributed control schemes are combined to form a Hybrid control arrangement. In hybrid control scheme, non conventional energy sources are employed with in hybrid system [46, 47]. The centralized arrangement is performed within each group and control arrangement with distributed approach synchronizes individual groups. Hybrid control method condenses the computation problem on master controller and also decrease single point breakdown problems by application of local controllers. Numbers of papers are detailed in literature which explained control strategies in power flow management in integration of energy by renewable systems. Torreglosa et al. [48] presented "Hierarchical control scheme which includes slave and master control strategy for hybrid system". The master controller was used to choose the energy source depending on the running cost and slave controller maintained the voltage within limits. Malla et al. [49] controlled the DC-link voltage by incorporating PWM inverter thus maintains the constant voltage across AC bus. Das et al. [50] regulated the output power from the sources by using PI/PID controllers based on the generated power and load demand. The optimization by the genetic algorithm is shows better performance than automatic generated strategy, improvement occurred in settling time and deviation of peak transient. Uzunoglu $M$ et al. [51] developed a "Dynamic model for PV/FC/UC hybrid power generation system". The load demand is achieved by PV and FC system and if it is beyond the limit then the UC bank meets the load demand.

\section{Conclusion}

Energy management strategies are necessary to achieve highest system reliability, operation efficiency and reduction of operating cost in an integrated energy by renewable source .For the design of hybrid energy by renewable system number of strategies are available, the available and currently under research strategies are summarized in this paper. Contemporary status and future potentials in the control of the systems with hybrid power are deliberated. Among the control strategies neural network, fuzzy and neuro fuzzy based are the promising in the design including system sizing, performance control and power management of hybrid energy by renewable systems. However more research has to be carried out for the effective forecasting of the load and intermittency due to weather conditions. A list of reference papers is added to help the present researcher in the region of hybrid energy by renewable system.

\section{References}

[1] S.M.Zaharee, M. KhalajiAssadi and R. Saidur, "Application of Artificial Intelligence Methods for Hybrid Energy System Optimiza- tion”, Renewable and Sustainable Energy Reviews, vol 66, 2016, pp. $617-630$.

[2] Erdinc O, Uzunoglu M, "Optimum Design of hybrid renewable systems: over view of different approaches", Renewable and Sustainable Energy Reviews, vol 12, 2012,pp. 1412-25.

[3] C. Wang and M. H. Nehrir, "Power Management of a Stand-Alone Wind/PV/Fuel Cell Energy System," IEEE Energy Conversion, Vol 23, No. 3, 2008, pp. 957-967.

[4] N. A. Ahmed, M. Miyatake and A. K. Al-Othman, "Power Fluctuations Suppression of Stand-Alone Hybrid Generation Combining Solar Photovoltaic/Wind Turbine and Fuel Cell Systems," Energy Conversion and Management, Vol. 49, No. 10, 2008, pp. 27112719.

[5] R. Carapellucci, L. Giordano, "Modeling and optimization of an energy generation island based on renewable technologies and hydrogen storage systems", International Journal of Hydrogen Energy, Vol. 37, 2012, pp. 2081-2093.

[6] Sanjit Kumar Kaper and Niraj Kumar Choudhary, "A Review of Power Management and Stability Issues in Microgrid", 1st IEEE International Conference on Power Electronics.Intelligent Control and Energy Systems, 2016.

[7] Upadhyay s, Sharma MP, "A review on configurations, control and sizing methodologies of hybrid energy systems", Renewable sustain energy Rev, vol 38, 2014, pp.47-63.

[8] M.Vaccaria,G.M.Mancusoa ,J.Riccardib ， M.Cantùc and G.Pannocchiaa, "A Sequential Linear Programming algorithm for economic optimization of Hybrid Renewable Energy Systems", Journal of Process Control, October 2017.

[9] Chiang, H.C., Ma, T.T., Cheng, Y.H., Chang, J.M., Chang, W.N., "Design and implementation of a hybrid regenerative power system combining grid-tie and uninterruptible power supply functions", IET Renew. Power Gener., 2010, 4, (1), pp. 85-99.

[10] Hugo Morais, Pe'ter Ka'da', Pedro Faria, Zita A. Vale , H.M. Khodr, "Optimal scheduling of a renewable micro-grid in an isolated load area using mixed-integer linear programming", Renewable Energy, Vol.35,2010,pp.151-156.

[11] E. Dursun, O. Kilic, Comparative evaluation of different power management strategies of a stand-alone PV/Wind/PEMFC hybrid power system" International Journal of Electrical Power and Energy Systems, Vol.34, pp. 81-89, 2012.

[12] Gupta A, Saini R, Sharma M (2010) Steady-state modeling of hybrid energy system for off grid electrification of cluster of villages. Renewable Energy 35:520-535. doi:10.1016/j.renene.2009.06.014.

[13] P.L. Zervas, H. Sarimveis, J.A. Palyvos, N.C.G. Markatos, Modelbased optimal control of a hybrid power generation system consisting of photovoltaic arrays and fuel cells", Journal of Power Sources, Vol. 181, pp. 327-338,2008.

[14] P. Thounthong, V. Chunkag, P. Sethakul, S. Sikkabut, S. Pierfederici, B. Davat,Energy management of fuel cell/solar cell/supercapacitor hybrid power source", Journal of Power Sources, Vol. 196, pp. 313\{324, 2011.

[15] Ipsakis D, Voutetakis S, Seferlis P, Stergiopoulos F, Papadopoulou $\mathrm{S}$, Elmasides C. "The effect of the hysteresis band on power management strategies in a stand-alone power system". Energy 2008;33(10):1537-50.

[16] Y. Zhang, H.J. Jia and L. Guo, "Energy Management Strategy of Islanded Microgrid Based on Power," IEEE PES Innovative Smart Grid Tech., pp. 1-8, 2012.

[17] DiegoFeroldi,Lucas NietoDegliuomini,MartaBasualdo, "Energy management of a hybrid system based on wind-solar power sources and bioethanol",2013;91: 1440-1455.

[18] Benoît Robyns, Arnaud Davigny and Christophe Saudemont, "Methodologies for supervision of Hybrid Energy Sources based on Storage Systems - A survey", Mathematics and Computers in Simulation, Volume 91, May 2013, Pages 52-71.

[19] Liao Z, Ruan X. A novel power management control strategy for stand-alone photovoltaic power system. In: Proceedings of the IEEE 6th international power electronics and motion control conference, IPEMC'09; 2009.p. 445-9. 
[20] Dahmane M, Bosche J, El-Hajjaji A, Dafarivar M. Renewable energy management algorithm for stand-alone system. In: Proceedings of the international conference onrenewable energy research and applications, ICRERA; 2013.p.621-6.

[21] Bhakta S, Mukherjee V, Shaw B. Techno-economic analysis of standalone photovoltaic/wind hybrid system for application in isolated hamlets of North-East India. J Renew Sustain Energy 2015;7(2):023126

[22] Sen R, Bhattacharyya SC. Off-grid electricity generation with renewable energy technologies in India: an application of HOMER Renew Energy 2014; 62:388-98.

[23] Abedi S, Alimardani A, Gharehpetian G, Riahy G, Hosseinian S. A comprehensive method for optimal power management and design of hybrid RESbased autonomous energy systems. Renew Sustain Energy Rev 2012; 16 (3):1577-87.

[24] Dennis Barley C, Byron Winn C. Optimal dispatch strategy in remote hybrid power systems. Sol Energy 1996; 58(4):165-79.

[25] Wenbo Shi, Na Li, Chi-Cheng Chu and Rajit Gadh, "Real-Time Energy Management in Microgrids", IEEE transactions on microgrid, Vol :8 issue 1.

[26] Dali M, Belhadj J, Roboam X. Theoretical and experimental study of control and energy management of a hybrid wind-photovoltaic system. In: Proceedings of the 8th international multi-conference on systems, signals and devices, SSD; 2011. p. 1-7.

[27] Zoubir Roumila ,Djamila Rekioua and Toufik Rekioua, "Energy management based fuzzy logic controller of hybrid system wind/photovoltaic/diesel with storage battery", International Journal of Hydrogen Energy,Volume 42, Issue 30, 27 July 2017, Pages:19525-19535.

[28] Kwi-SeongJeong, Won-Yong Lee and Chang-SooKim,'Energy management strategies of a fuel cell/battery hybrid system using fuzzy logics", Journal of Power Sources, Vol No 145, 2005,pp. 319-326

[29] Mehdi Hosseinzade and FarzadRajaeiSalmasi, "Power management of an isolated hybrid AC/DC micro-grid with fuzzy control of battery banks", IET Renewable Power Generation Volume 9, Issue 5, 2015, pp.484-493.

[30] Baziar A, Kavousi -Fad A, "Considering uncertainity in the optimal energy management of renewable micro-grids including storage devices", Renew Energy, 2013:158-66.

[31] Feroldi D, Degliuomini LN, Basualdo M. Energy management of a hybrid system based on wind-solar power sources and bioethanol. ChemEng Res Design 2013;91(8):1440-55

[32] A.Tabanjat, M.Becherifb , D.Hisselc and H.S.Ramadanbd, "Energy management hypothesis for hybrid power system of H2/WT/PV/GMT via AI techniques", International Journal of Hydrogen Energy,July 2017.

[33] Bruni G, Cordiner S, Mulone V, Rocco V, Spagnolo F. A study on the energy management in domestic micro-grids based on model predictive control strategies. Energy Convers Manag 2015;102:50 8 .

[34] Basir Khan MR, Jidin R, Pasupuleti J. Multi-agent based distributed control architecture for microgrid energy management and optimization. Energy Convers Manag 2016;112:288-307.

[35] Brka A, Kothapalli G, Al-Abdeli YM. Predictive power management strategies for stand-alone hydrogen systems: Lab-scale validation. Int J Hydrogen Energy 2015; 40(32):9907-16.

[36] Upadhyay S, Sharma MP. Selection of a suitable energy management strategy for a hybrid energy system in a remote rural area of India. Energy 2016; 94:352-66.

[37] Bonissone PP. Soft computing: the convergence of emerging reasoning technologies. Soft Comput 1997;1(1):6-18.

[38] Palma-Behnke R, Benavides C, Aranda E, Llanos J, Sáez D. Energy management system for a renewable based microgrid with a demand side management mechanism. In: Proceedings of the IEEE symposium on computational intelligence applications in smart grid, CIASG; 2011. p. 1-8.

[39] Azmy AM, Erlich I. Online optimal management of PEMFuel cells using neural networks. IEEE Trans Power Deliv 2005;20(2):1051-8.
[40] Hatti M, Tioursi M. Dynamic neural network controller model of PEM fuel cell system. Int J Hydrogen Energy 2009;34(11):5015-21.

[41] Chen, Y.K., Wu, Y.C., Song, C.C., Chen, Y.S.: 'Design and implementation of energy management system with fuzzy control for DC micro-grid systems', IEEE Trans. Power Electron., 2013, 28 (4), pp. 1563-1570.

[42] O. Erdinc, B. Vural, M. Uzunoglu, A wavelet-fuzzy logic based energy management strategy for a fuel cell/battery/ultra-capacitor hybrid vehicular power system", Journal of Power Sources, Vol. 194, pp. 369-380,2009.

[43] Valenciaga F,Puleston PF.Supervisor control for a stand-alone hybrid generation system using wind and photovoltaic energy. IEEE Trans Energy Convers 2005;20(2):398-405.

[44] Zaheeruddin and MunishManas , "Renewable energy management through microgrid central controller design: An approach to integrate solar, wind and biomass with battery", Energy Reports, Volume 1, November 2015, Pages 156-163.

[45] Nehrir M H,Wang C,Strunz K,Aki H,Rama kumar R,Bing J,etal. A review of Hybrid renewable /alternative energy systems for electric power generation: configurations, control, and applications. IEEE Trans Sustain Energy 2011; 2(4):392-403.

[46] $\mathrm{KoH}$,Jats kevich J. Power quality control of wind-hybrid power generation system using fuzzy-LQR controller.IEEE Trans Energy Convers 2007;22(2):516-27.

[47] Jiang Z,Douga 1R.Hierarchical microgrid paradigm for integration of distributed energy resources. In:Proceedings of the IEEE Power Engineering Society general meeting. Pitts burgh (PA); July,2008,pp.20-24.

[48] Torreglosa JP,García P,Fernández LM,Jurado F.Hierarchical energy management system for stand-alone hybrid system based on generation costs and cascade control. Energy Convers Manag 2014; 77: 514-26.

[49] Malla SG,Bhende CN.Voltage control of stand-alone wind and solar energy system. Electr Power Energy Syst 2014; 56:361-73.

[50] Das DC, Roy AK, Sinha N.GA based frequency controller for solar thermal diesel-wind hybrid energy generation/energy storage system. Electrical Power Energy System 2012;43:262-79.

[51] Uzunoglu M,Onar OC,Alam MS. Modeling, control and simulation of a PV/FC/UC based hybrid power generation system for standalone applications. Renew Energy 2009; 34:509-20. 